\title{
AS MUDANÇAS CLIMÁTICAS NA PROVÍNCIA DO NIASSA E SEU IMPACTO PARA A AGRICULTURA
}

\author{
B. J. MACHILI \\ Universidade Rovuma \\ ORCID ID: https://orcid.org/0000-0003-3620-1368 \\ boavidajorgemachili@gmail.com
}

Submetido 29/05/2020 - Aceito 18/12/2020

DOI: $10.15628 /$ holos.2020.10281

\section{RESUMO}

Os impactos das mudanças climáticas insidem no aumento da temperatura e na diminuição dos níveis de precipitação, podendo reflectir-se sobremaneira na produtividade agrícola, comprometendo de certa forma, o rendimento deste sector económico. É neste contexto que nos propusemos a reflectir a forma como as mudanças climáticas têm afectado a agricultura na província do Niassa, com o objectivo de analisar o impacto das mudanças climáticas na agricultura. Especificamente caracterizar a alteração da temperatura e precipitação; explicar como tal alteração podem influenciar na degradacao de culturas e apresentar alternativas de culturas resilientes às mudanças climáticas e outras
\end{abstract}

alternativas que garantem o desenvolvimento do sector agrário. A entrevista, a análise de dados termopluviométricos, estudo documental e a revisão bibliográfica, são elementos que apoiaram a concretizar a pesquisa. A alteração de padrões climáticos, principalmente o aumento da temperatura e diminuição ou aumento da precipitação, afectam o sector agrário, com maior enfoque na degradação das culturas. O recurso ao uso de culturas adaptativas e resilientes às mudanças climáticas, associadas as novas tecnologias, passa a ser uma alternativa para assegurar o equilíbrio dos níveis de produção e garantir a segurança alimentar.

Palavras-chave: mudanças climáticas; alteração da temperatura e precipitação; degradação de culturas de agrícola; culturas resilientes; Província do Niassa.

\section{CLIMATE CHANGE IN NIASSA PROVINCE AND ITS IMPACT ON AGRICULTURE}

\begin{abstract}
The impacts of climate change affect the increase in temperature and the decrease in precipitation levels, which may be reflected in agricultural productivity, compromising, in a certain way, the income of this economic sector. It is in this context that we set out to reflect how climate change has affected agriculture in Niassa province, with the aim of analyzing the impact of climate change on agriculture. Specifically characterize the change in temperature and precipitation; explain how such change can influence crop degradation and present crop alternatives resilient to climate change and other alternatives that
\end{abstract}

guarantee the development of the agrarian sector. The interview, the analysis of thermopluviometric data, documentary study and the bibliographic review, are elements that supported to carry out the research. The change in climatic patterns, mainly the increase in temperature and the decrease or increase in precipitation, affect the agricultural sector, with a greater focus on crop degradation. The use of adaptive crops that are resilient to climate change, associated with new technologies, becomes an alternative to ensure the balance of production levels and ensure food security.

Keywords: climate change; change in temperature and precipitation; degradation of agricultural crops; resilient cultures; Niassa Province.

HOLOS, Ano 36, v.7, e10281, 2020 


\section{CONTEXTUALIZAÇÃO}

Moçambique possui o clima tropical e subtropical com uma variação da temperatura de cerca de $5^{\circ} \mathrm{C}$ entre os meses frios (Junho, Julho e Agosto) e os meses mais quentes (Dezembro Janeiro e Fevereiro. Geograficamente as temperaturas são mais altas ao longo da costa e na região Sul e mais baixas na zonas do interior e região Norte do pais (ZOLHO, 2010:25).

A província do Niassa é a maior do país com uma superfície de aproximadamente 129 mil Km${ }^{2}$, situando-se no extremo Noroeste do país, entre as latitudes $11^{\circ} 25^{\prime}$ Norte e $15^{\circ} 26^{\prime}$ Sul e as longitudes $35^{\circ} 58^{\prime}$ Este e $34^{\circ} 30^{\prime}$ Oeste. Faz fronteira a Norte com a Tanzânia, a Oeste, com a República do Malawi, a Leste com a Província de Cabo Delgado e a Sul com as Províncias de Nampula e Zambézia. O clima é caracterizado por duas estações (chuvosa e seca). A estação chuvosa vai de Outubro a Março e a estação seca de Abril a Setembro. Os meses de Abril e Outubro, contudo, são considerados como de transição, podendo alterar suas características de meses de seca (Abril) ou chuva (Outubro) de um ano para outro. No período seco, a temperatura média, na província, varia de 15 a $25^{\circ} \mathrm{C}$ e no período chuvoso, eleva-se a mais de $25^{\circ} \mathrm{C}$, raramente superando, contudo, os $30^{\circ \mathrm{C}}$ (GPN, 2017).

As mudanças climáticas em Moçambique e na Província de Niassa e o impacto destas no sector agrário, tem sido um problema visualizado em níveis globais, merecendo uma análise profunda e conjunta em busca de soluções de mitigação e adaptação, envolvendo todas facetas de desenvolvimento da sociedade. De certo, LIMA, CAVALCANTE \& PEREZMARIN (2011:4), observam que para buscar alternativas de solução de um problema ligado às mudanças climáticas "implica influir no comportamento social, económico e político da sociedade e, desenvolver acções dirigidas para prevenção e controle".

Para o efeito, todos actores envolvidos nesta causa, são chamados a intervir com aç̧ões práticas concretas em meios e estratégias. É necessário o enquadramento de iniciáticas locais, nacionais e internacionais (individuais e colectivas), apoiadas com os sectores governamentais e não governamentais a todos os níveis.

Face a isso, 154 países do mundo reuniram-se em Nova York em 1992, tendo adoptado a Convenção sobre Mudança do Clima (Convenção Quadro das Nações Unidas sobre Mudança do Clima), que entrou em vigor em 21 de Março de 1994, onde até em meados de 1997, a Convenção passou a contar com 165 países membros. E, através do Artigo 3 da Convenção é possível perceber que objectivo central era de minimizar a emissão de gases de efeito estufa, permitindo que os ecossistemas se adaptem naturalmente à mudança do clima, garantindo produção de alimentos e o desenvolvimento económico sustentável (MCT, s/d).

A preocupação com os efeitos das mudanças climáticas passou a ser de tamanha importância nas nações africanas, com maior destaque para o sector agrário. Por exemplo, no âmbito da Convenção Quadro das Nações Unidas sobre as mudanças climáticas (CQNUMC), em 2007 a República de Cabo Verde, através do Ministério do Ambiente e Agricultura, 
elaborou o Programa de Acção Nacional de Adaptação às Mudanças Climáticas 2008-2012. A iniciativa financiada pelo Programa das Nações Unidas para o Desenvolvimento (PNUD) em 2005, visava identificar sectores-chave e mobilizar recursos para atender opções de adaptação prioritárias segundo as necessidades e preocupações urgentes e imediatas das populações mais vulneráveis face aos efeitos nefastos da variabilidade e mudanças climáticas (MAA, 2007).

A par deste cenário, em 2005 o Ministério para Coordenação da Acção Ambiental (MICOA) havia avançado com um estudo sobre a avaliação da vulnerabilidade as mudanças climáticas e estratégias de adaptação, olhando a situação de vulnerabilidade a eventos climáticos em Moçambique, suas causas, impactos e estratégias de adaptação.

Os resultados do estudo referido no paragrafo anterior, permitiram ao Governo moçambicano através do MICOA, elaborar em Dezembro de 2007, o Programa de Acção Nacional para a Adaptação às Mudanças Climáticas (NAPA), tendo priorizado as seguintes acções: fortalecimento do sistema de aviso prévio, fortalecimento das capacidades dos produtores agrários a lidar com as mudanças climáticas, redução do impacto das mudanças climáticas nas zonas costeiras e gestão dos recursos hídricos no âmbito das mudanças climáticas (MICOA, 2007).

O NAPA constituiu ponto de partida para a definição de estratégias de operacionalização de acções concretas que respondam os desafios do Governo e da população moçambicana na mitigação e adaptação dos efeitos das Mudanças Climáticas (MC). Para responder este desafio, em Junho de 2010, o MICOA desenhou a Estratégia e Plano de Acção de Género, Ambiente e Mudanças Climáticas como forma de contribuir para o empoderamento da mulher e das comunidades locais, através do acesso às tecnologias e outras actividades para mitigação e adaptação às mudanças climáticas e do uso sustentável dos recursos naturais. A semelhança desta perspectiva, em 13 de Novembro de 2012, na 39ạ Sessão do Conselho de Ministros do Governo moçambicano, foi aprovada a Estratégia Nacional de Adaptação e Mitigação de Mudanças Climáticas (ENAMMC) 2013 - 2025.

Prevendo o aumento irreversível dos impactos das $M C$ em frequência e intensidade, o Governo moçambicano através do MICOA, adoptou a ENAMMC como documento orientador com objectivo de identificar áreas chave de actuação e acções que podem ser levadas a cabo com vista a diminuir as gravidades dos impactos, através de aç̧ões de adaptação e de redução dos riscos climáticos e aproveitar as oportunidades de mitigação e desenvolvimento de baixo carbono que contribuam para a redução das emissões de GEE (MICOA, 2012).

Esta pesquisa revela ser mais um momento de reflexão da preocupação sobre o impacto das mudanças climáticas na agricultura, trazendo à debate, aspectos relevantes que merecem serem observados com maior atenção com toda a sociedade humana a nível local, nacional e internacional. 
As ideias apresentadas neste estudo, partem das constatações da conjuntura internacional para perceber o cenário a nível nacional e fazer a interpretação do fenómeno à realidade da Província de Niassa.

Os dados termo-pluviométricos fornecidos pelo Instituto Nacional de Meteorologia, Delegação de Niassa e do sector de Agrometeorologia do Instituto de Investigação Agrária de Moçambique (IIAM) - Centro Regional Norte, foram a base da análise da manifestação da temperatura e precipitação na Província de Niassa, num período de 39 anos (1980-2019). Igualmente o IIAM forneceu informações sobre o impacto das alterações registadas na temperatura e precipitação sobre as culturas, incluindo a capacidade de retenção da água no solo e suas repercussões na humidade e fertilidade do solo e estratégias de adaptação às mudanças climáticas na província e no país. Estes dados foram alicerçados com discussões apresentadas em estudos internacionais e nacionais e documentos elaborados por instituições afins, como pode ser conferido nos pontos que se seguem.

\section{QUADRO TEÓRICO}

\subsection{Mudanças climáticas e a manifestação da temperatura e precipitação}

A análise sobre as mudanças climáticas é feita através do discurso orientado na alteração de padrões de temperatura e precipitação, como principais indicadores. As ideias apresentadas por autores no geral, apresentam uma base lógica do impacto da alteração de padrões climáticos sobre a actividade agrícola.

Partindo do pressuposto sobre o qual o planeta Terra se encontra em constante mudança por factores naturais, é aceitável afirmar que as mudanças climáticas têm um início impreciso. As mudanças de padrões de temperatura e precipitação existiram desde a segunda geração da atmosfera, que a partir de uma forte radiação solar, começou a registar-se a dissociação de gases atmosféricos, como por exemplo a dissociação do Vapor de Água que originou o Oxigénio e Hidrogénio, o Amoníaco originou o Azoto/Nitrogénio e o Metano originou o Carbono. Associado a isso, a atmosfera sempre recebeu gases de efeito estufa, através das erupções vulcânicas, combustão da matéria orgânica por fenómenos naturais como relâmpagos e movimentos ascendentes do ar.

A acção antrópica contribuiu na emissão de gases para atmosfera através da combustão orgânica e inorgânica, e, no outro sentido, pelo facto de devastar a flora para fins económicos. Outra sim, é a responsabilização aos enventos técnicos que precipitaram a revolução industrial e agrária, aliadas à tecnologia. Com estes condicionantes, o acúmulo de gases de efeito estufa, dentre os quais se destacam o dióxido de carbono, metano e os óxidos nitrosos, aumentou no século XVIII, tendo despertado atenção a humanidade sobre a poluição atmosférica e outros problemas ambientais surgidos de suas acções (OLIVIERI, 2009). 
Assim, no século XIX surgiu o despertar da humanidade na consciência sobre os problemas ambientais, onde a população do planeta Terra passou a manifestar através de documentos escritos, movimentos populares e associações, tendo culminado com o surgimento das ciências do ambiente nos anos 1980 do século XX. Desde então, as ideias sobre a causa ambiental maximizaram-se, surgindo a necessidade de realizar conferências internacionais e frequentes debates, elaborando documentos contendo linhas directrizes para a mitigação dos problemas ambientais (OLIVIERI, 2009).

Uma das prioridades das nações a nível do mundo é o efeito das mudanças climáticas. Com este propósito e reconhecendo a gravidade de elevados índices de aquecimento a nível do globo, aliadas ao aumento de poluentes e a devastação da floresta, em 2007 as Nações Unidas elaboraram a convenção sobre as mudanças climáticas, conhecida por Convenção Quadro das Nações Unidas sobre as mudanças climáticas (CQNUMC), um documento onde foram ratificados elementos básicos que visam a diminuição da emissão de gases de efeito estufa para mitigar os efeitos das mudanças climáticas.

Segundo o Ministério da Ciência e Tecnologia (s/d:5), "Mudança do clima significa uma alteração de clima que possa ser directa ou indirectamente atribuída à actividade humana que altere a composição da atmosfera mundial e que se some àquela provocada pela variabilidade climática natural observada ao longo de períodos comparáveis".

Em África os níveis de emissão de GEE estão em 7\%, resultantes principalmente das queimadas descontroladas, desflorestamento e conversões da terra (ZOLHO, 2010).

Este cenário faz com que os níveis de temperatura aumentem substancialmente, colocando em risco os ecossistemas naturais e o desenvolvimento da agricultura. Com efeito, as projecções do IPCC indicam que o continente africano até 2020, irá registar um aumento da temperatura média de $1,3^{\circ} \mathrm{C}$ a $5,18^{\circ} \mathrm{C}$ e uma diminuição de 5 a $20 \%$ da precipitação média anual, um aumento de correntes quentes e diminuição de dias frios (ZOLHO, 2010).

Sobre o caso, Moçambique regista o aumento da frequência do número de dias quente e a diminuição da frequência do número de dias e noites frias desde 1960, prevendo-se o aumento de secas, temperaturas altas e grande evaporação (QUEFACE, 2007 Apud ZOLHO, 2010).

Com a prevalência deste cenário, projecta-se que a temperatura venha aumentar na ordem de $2,5^{\circ} \mathrm{C}$ a $3^{\circ} \mathrm{C}$ até 2060 , e $1,4^{\circ} \mathrm{C}$ a $4,6^{\circ} \mathrm{C}$ até 2090 (MCSWEENEYL, et al., 2003 Apud ZOLHO, 2010). Ou seja, as temperaturas máximas extremas diárias irão subir acima dos $35^{\circ} \mathrm{C}$ em todo o país entre 2080-2100 (QUEFACE, 2007 Apud ZOLHO, 2010).

Os eventos extremos climáticos (cheias, secas e ciclones) são acelerados pela força das MC, colocando em risco a actividade agrícola a nível do país, com destaque para a região costeira. 
As mudanças climáticas trazem consigo efeitos directos e indirectos ligados a alteração da estrutura e normal funcionamento dos ecossistemas terrestre, o desenvolvimento de culturas agrícolas e a vida da população. Por isso:

efeitos negativos da mudança do clima significa as mudanças no meio ambiente físico ou biota resultantes da mudança do clima que tenham efeitos deletérios significativos sobre a composição, resiliência ou produtividade de ecossistemas naturais e administrados, sobre o funcionamento de sistemas socioeconómicos ou sobre a saúde e o bem-estar humanos ${ }^{1}$.

A nossa discussão centra-se mais no impacto das mudanças climáticas para a alteração da temperatura e consequente diminuição ou aumento da precipitação. Sobre o caso, Moçambique é um dos países afectados pelas mudanças climáticas, associados aos eventos extremos climáticos como as cheias e inundações e as secas.

O segundo relatório de revisão de Moçambique, sobre o Mecanismo Africano de Revisão de Pares (MARP) de 2019, explica que o país ocupa o terceiro lugar entre os países africanos mais expostos aos riscos de desastres relacionados com o clima e na $43^{a}$ posição em todo o mundo, de 173 países.

2.2. A alteração dos níveis de temperatura e precipitação e seu impacto na agricultura

Como referido nos pontos anteriores e em concordância com as ideias de OLIVEIRA \& ALVES (2011:34), as dificuldades no sector agrário (a degradacao de culturas), estão associadas as altas taxas de concentração de $\mathrm{CO} 2$ na atmosfera, ao aumento da temperatura e ao aumento na frequência de eventos climáticos extremos que modificam os níveis de precipitação.

Os níveis de precipitação resultantes das mudanças climáticas, sejam eles altos ou baixos, propiciam por um lado, a maior evaporação e secura do solo, criando problemas para o desenvolvimento de culturas que não se adaptam às secas que também podem fazer surgir pragas que danificam parte da produção. Por outro lado, a ocorrência de cheias e inundações provocadas por quedas pluviométricas anormais, abrem espaço para a devastação das culturas da população ribeirinha no nosso país, obrigando-a a abandonar as suas terras².

Segundo o relatório do Mecanismo Africano de Revisão de Pares (MARP) de 2019, a parte mais afectada pela seca no país centra-se nas províncias de Gaza e Maputo, com

${ }^{1}$ MINISTÉRIO DA CIÊNCIA E TECNOLOGIA (MCT). Convenção sobre mudança do clima. s/d. p.5.

${ }^{2}$ Em 2017 a seca deslocou mais de 170.000 pessoas em Moçambique (RM, 2019:80).

HOLOS, Ano 36, v.7, e10281, 2020 
destaque para a região de Pafuri (com clima semi-árido), distritos adjacentes no sul de Manica e Inhambane, assim como os vários distritos no norte de Manica, sul de Tete e, em pequena escala, partes de Cabo Delgado, com destaque para a região da Mocímboa da Praia (com clima semi-árido) e Norte de Nampula.

\section{MUDANÇAS CLIMÁTICAS NA PROVÍNCIA DE NIASSA}

\subsection{Aleração dos níveis de temperatura e precipitação}

Mesmo que a Província de Niassa geoestrategicamente se localize no interior do país, num espaço geográfico de relevo relativamente alto, onde se encontra o planalto de Lichinga (com altitude mais saliente do país - $1374 \mathrm{~m}$ ), as mudanças climáticas afectam significativamente a temperatura e a precipitação. Os níveis de precipitação tendem a diminuir na última década, comparando com as décadas anteriores e a temperatura aumenta progressivamente. Essa manifestação climática enquadra-se no contexto das mudanças climáticas globais que preocupa os habitantes de todo o planeta.

Evidentemente, a temperatura média anual da Província de Niassa nos últimos 5 anos está acima dos $20^{\circ} \mathrm{C}$, comparando com os anos anteriores que rondava no intervalo de 19 a $20^{\circ} \mathrm{C}$ em média. (vide gráfico 1 ).

Os níveis de precipitação na Província de Niassa são irregulares em termos de médias da queda pluviométrica por ano desde 1980 a 2019, registando baixa pluviosidade em certos anos, principalmente em 1987, 1992, 1998, 2007 e 2016. A precipitação teve o seu pico em 2002, tendo atingido $1809 \mathrm{~mm}$. Aliado às mudanças climáticas e consequente aumento da temperatura, desde 2002 até 2019, as quedas pluviométricas tendem a diminuir gradualmente (Vide gráfico 2 ).

Tal manifestação climática diminui o nível de humidade do solo, pelo facto de registarse maior evaporação, deixando a terra seca e relativamente quente em todos os períodos do ano. Aliás, QUEFACE (2007) Apud ZOLHO (2010) refere que a diminuição da precipitação e o aumento da temperatura diurna e anual em Moçambique, poderá de certa forma, prolongar as secas e abrir espaço para o surgimento de outros problemas associados às mudanças climáticas, como por exemplo, as cheias e inundações. 
Gráfico 1. Temperatura média anual (1980 - 2019)

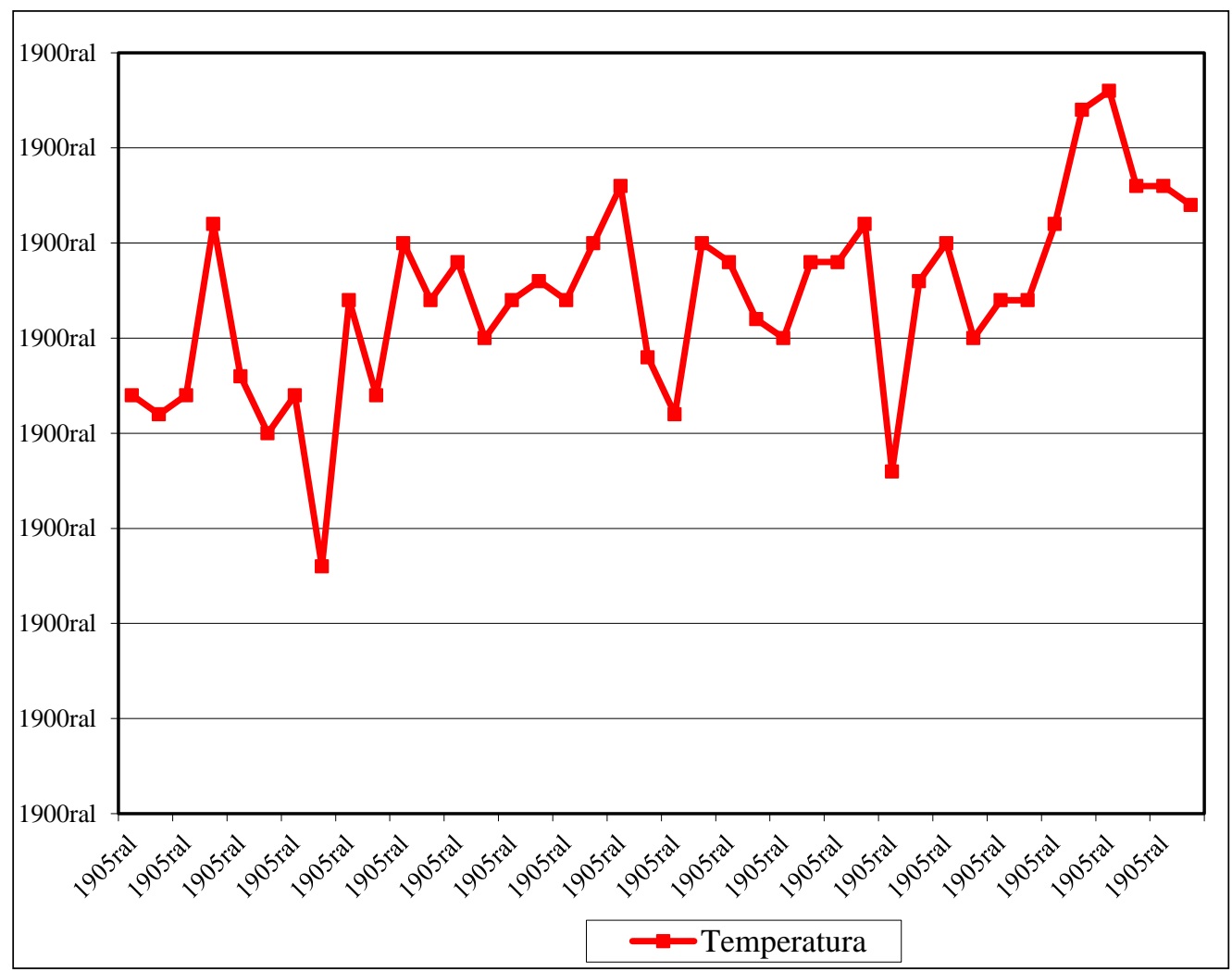

Fonte: INAM/IIAM, 2019

Gráfico 2. Precipitação média anual (1980 - 2019)

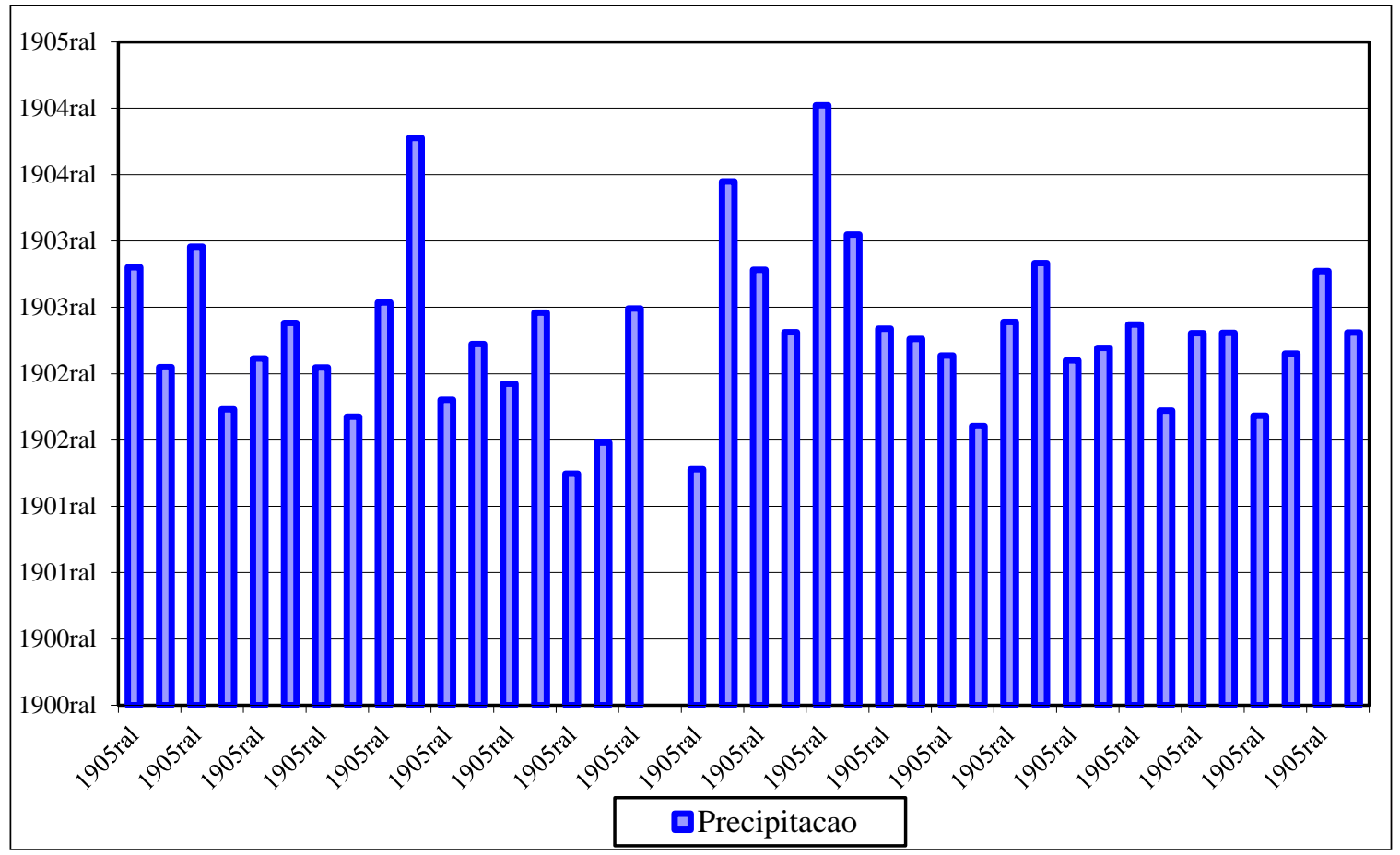




\subsection{O impacto do fluxo termo-pluviométrico na agricultura}

Na Província de Niassa, o aumento da temperatura e a diminuição da precipitação, influenciam significativamente na degradação das culturas e na baixa produção do sector familiar e empresarial.

O Plano Estratégico do Niassa 2018-2029, revelou que em 2015 foi realizado um estudo sobre riscos e adopção às mudanças climáticas de agricultores da Província de Niassa, onde a percepção dos agricultores de Lichinga ajudaram a perceber que nos últimos anos, o aumento da temperatura e a diminuição da precipitação, proporcionam o início tardio da queda da chuva, de Outubro para finais de Novembro ou início de Dezembro e a redução da estacão chuvosa, constituindo principais entraves para o desenvolvimento da agricultura e consequente baixo rendimento neste sector económico (GPN, 2017).

Sobre o caso, o estudo realizado com os técnicos do Instituto de Investigação Agrária de Moçambique (IIAM), Centro Regional Norte, os sectores de cereais, leguminosas e hortícolas, revelaram que o recuo do início das chuvas provoca estiagem, afectando as culturas que não se adaptam as secas, com destaque à cultura de arroz e as hortícolas (couve tronchuda, alface, repolho, cebola e tomate).

Os gráficos 3 e 4 apresentam o comportamento da temperatura e precipitação nos meses de Outubro (mês que começa a se registar a precipitação na província de Niassa com baixa queda pluviométrica) e o mês de Janeiro (mês que se regista elevada queda pluviométrica).

Gráfico 3. Comportamento da temperatura nos meses de Outubro e Janeiro (1980 - 2019)

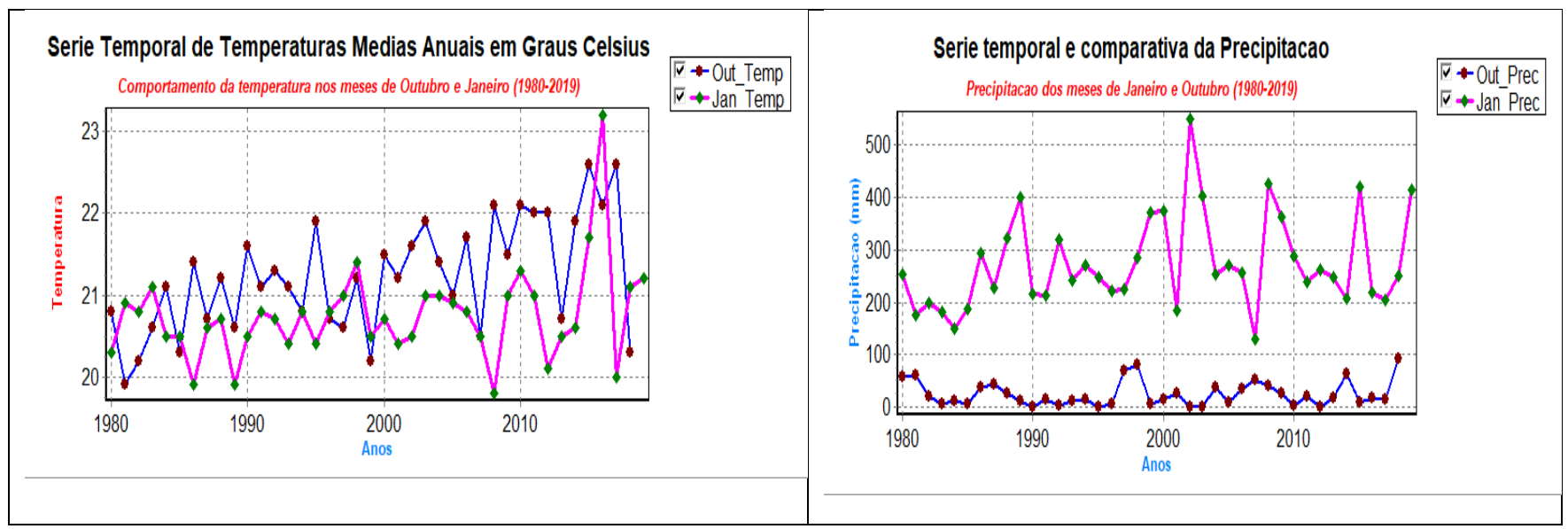

Fonte: INAM/IIAM, 2019

O estudo de avaliação participativa realizado a nível do país pela Direcção Nacional de Gestão Ambiental, e que culminou com a elaboração do Programa de Acção Nacional para a Adaptação às Mudanças Climáticas (NAPA), tendo abrangido em Niassa os Distritos de Cuamba e 
Maúa, revelou que as MC provocam a perda de culturas, secagem de fontes de água que podiam facilitar a irrigação, redução da produção, subida de preços de produtos agrícolas, eclosão de doenças, incluindo pragas, perda da biodiversidade, entre outros (MICOA, 2007). Com isso, o sector agrário deve estar preparado dos efeitos das MC, criando mecanismos resilientes.

O inicio tardio das quedas pluviomericas com que os agricultores realizem a actividade da sementeira tardiamente, com tendencias a passar para os fins de Novembro e primeira quinzena de Dezembro (vide gráfico 5).

Gráfico 5. Cálculo do início da sementeira com base no critério de $20 \mathrm{~mm}$ em $\mathbf{2}$ dias e não observância de 10 dias ou mais sem chuva nos próximos 30 dias.

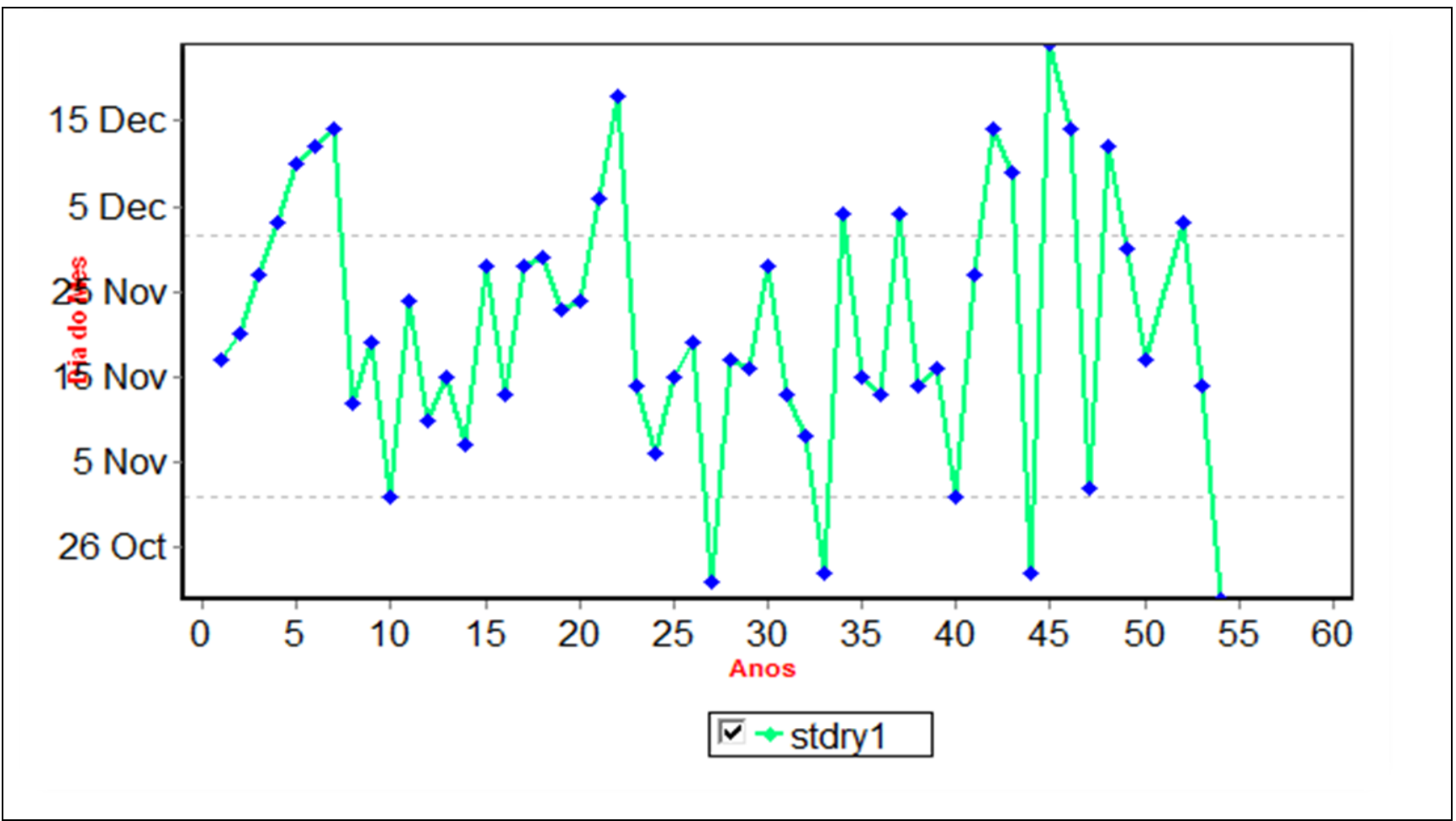

Fonte: INAM/IIAM, 2019

\section{DESAFIOS DO SECTOR AGRÁRIO EM RESPOSTA ÀS MUDANÇAS CLIMÁTICAS}

A diminuição dos meses de precipitação, a quantidade da pluviosidade e o recuo dos meses de início das chuvas, afecta sobremaneira, os excedentes agrícolas, colocando vulneráveis as famílias que servem da agricultura, como sector base de subsistência (MICOA, 2012).

Necessita-se de actividades bem elaboradas e planificadas, em estreita colaboração interinstitucional para a prevenção e redução do impacto dos desastres naturais. Por outro lado é essencial o fortalecimento das instituições com meios técnicos e financeiros que permitam uma 
monitoria sistemática de parâmetros ambientais assim como conduzir pesquisas académicas para melhor entender e interpretar os fenómenos que influenciam as mudanças climáticas, assim como uma forte componente educacional da população para melhor entender os avisos prévios, bem como a importância da preservação do meio ambiente (MICOA, 2007).

Uma das estratégias adoptadas pelo Governo moçambicano no sector agrário em resposta aos efeitos das MC é o uso de sementes adaptadas às secas e a implementação de um sistema de preparação do solo, que se adequa às sementes geneticamente modificadas.

Assim, o Ministério da Agricultura, através de IIAM de Niassa, tem vindo a melhorar o acesso a semente de boa qualidade, através da produção local de sementes e a realização de feiras comunitárias da semente melhorada, com tendência a multiplicar o rendimento agrícola.

Associado a esta iniciativa, e para garantir a segurança alimentar, o Ministério da Agricultura desenvolve outras acções como: alargamento das áreas com culturas perenes, através de produção e distribuição de plântulas; produção intensiva de hortícolas e outras culturas anuais; multiplicação de rama de batata-doce e estacas de mandioca como material tolerante à seca e para a substituição de variedades sensíveis a doença de podridão radicular da mandioca; aquisição e fornecimento de kits de equipamento de protecção e combate as pragas e doenças; a utilização intensiva de recursos hídricos, através da construção e reabilitação de sistemas de regadio, represas e fontes de água, bem como a aquisição e montagem do equipamento de regadio (exemplo, bombas pedestais), visando garantir intervenções sustentáveis (MICOA, 2005).

O MITADER chama atenção para a integração das estratégias locais de produção, adaptativas aos efeitos das mudanças climáticas. Contudo, observa que uma definição clara das estratégias locais a serem adoptadas por uma determinada comunidade em resposta a um evento climático de curta ou longa duração, passa por um estudo detalhado das características físico-geográficas, culturais, e sócio-económicas do local e da comunidade (MICOA, 2005).

Em entrevista com os tecnicos do IIAM de Niassa, percebeu-se que uma das saídas passa necessariamente pela implementação do sistema de cultivo misto e o uso de culturas resistentes à seca e que também se adaptam a multiplicidade de culturas e ambientes diferentes, como por exemplo a mexoeira, mapira, mandioca, feijão nhemba e amendoim. Pode-se também sofisticar o sistema de regadio que assegure a produção nos meses de estiagem.

Deve igualmente haver uma acção multi-sectorial, a ser coordenada pelo Instituto Nacional de Gestão de Calamidades (INGC), para responder os eventos extremos como cheias, secas e ciclones.

No conjunto das actividades a serem desenvolvidas, deve constar a elaboração de planos sectoriais por tipo de evento climático, nomeadamente plano de secas, ciclones e epidemias; 
formação e educação cívica das populações sobre as principais ameaças de eventos climáticos extremos e calamidades e as respectivas medidas de prevenção; capacitação institucional com pessoal técnico e meios materiais e equipamento adequado a prevenção; integração sectorial das acções de prevenção e nos programas de desenvolvimento (MICOA, 2005).

Tomando em conta que a população pobre é a mais vulnerável aos efeitos das MC, associado as particularidades sociais como o tipo de cultura e os hábitos e costumes alimentares da população (MICOA, 2005; MALUF \& ROSA, 2011), devem ser definidas estratégias multi-sectoriais de mitigação do problema, observando as particularidades sócio-culturais e fisionómicas de cada local.

Nesta senda de acção multi-sectorial, a área de Geo-engenharia propõe soluções técnicas para minimizar o aquecimento global como a filtragem de $\mathrm{CO}_{2}$ directamente do ar, a fertilização dos oceanos com uso de ferro adicionado para multiplicação de plâncton, a carbonatação mineral, formação artificial de nuvens para bloquear parte da energia do sol e até colocação de espelhos reflectores no espaço (vide tabela 1 ).

Tabela 1. Estratégias técnicas de redução do aquecimento global

\begin{tabular}{|c|c|c|c|c|}
\hline & $\begin{array}{l}\text { Viabilidade } \\
\text { (1 to } 10)\end{array}$ & $\begin{array}{l}\text { Custo } \\
\text { (\$ to } \\
\$ \$ \$)\end{array}$ & $\begin{array}{l}\text { Risco(1 } \\
\text { to } 10)\end{array}$ & Descrição geral e comentários \\
\hline $\begin{array}{l}\text { Armazenamento } \\
\text { geológico de } \mathrm{CO}_{2}\end{array}$ & 10 & $\$ \$$ & 4 & $\begin{array}{l}\text { CO } 2 \text { pode ser armazenado em } \\
\text { reservatórios de petróleo, minas de } \\
\text { carvão e aquíferos salinos. Estima-se que } \\
\text { reservatórios subterrâneos e aquíferos } \\
\text { salinos poderiam armazenar até } 200.000 \\
\text { gigatoneladas. }\end{array}$ \\
\hline $\begin{array}{l}\text { Filtragem de } \mathrm{CO}_{2} \\
\text { do ar }\end{array}$ & 4 & $\$ \$$ & 4 & $\begin{array}{l}\text { Extrair dióxido de carbono do ar } \\
\text { ambiente. }\end{array}$ \\
\hline $\begin{array}{l}\text { Fertilização do } \\
\text { oceano }\end{array}$ & 10 & $\$$ & 9 & $\begin{array}{l}\text { Adição de ferro ao oceano poderia } \\
\text { esfriar o planeta pelo plâncton que } \\
\text { absorve } \mathrm{CO} 2 \text {. }\end{array}$ \\
\hline 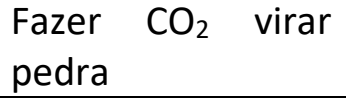 & 7 & $\$$ & 3 & Conhecido como carbonatação mineral. \\
\hline $\begin{array}{l}\text { Formação de } \\
\text { nuvens para } \\
\text { reflectir a luz do } \\
\text { sol }\end{array}$ & 6 & $\$ \$$ & 7 & $\begin{array}{l}\text { Não envolve captura de dióxido de } \\
\text { carbono. Mas o foco é sobre a } \\
\text { diminuição do calor pela reflexão ou } \\
\text { filtragem dos raios de sol que chegam. } \\
\text { Seria como um espelho para a radiação } \\
\text { solar incidente. }\end{array}$ \\
\hline
\end{tabular}




\begin{tabular}{l|l|c|c|l}
\hline $\begin{array}{l}\text { Reflectir a luz do } \\
\text { sol com um } \\
\text { espelho }\end{array}$ & 1 & $\$ \$ \$$ & 5 & $\begin{array}{l}\text { Espelho gigante no espaço posicionado } \\
\text { entre a Terra e o Sol para interceptar a } \\
\text { luz solar. }\end{array}$ \\
\hline
\end{tabular}

Fonte: MUYLAERT, M.S. et all., 2007 Apud MALUF \& ROSA, 2011:44

\section{CONSIDERAÇÕES FINAIS}

Os resultados da pesquisa deram a perceber que as mudanças climáticas que se manifestam no mundo e Moçambique no geral e na Província de Niassa em particular, contribuem significativamente no aumento da temperatura e diminuição da precipitação, com destaque para a última década (2000 - 2019). Os prejuízos repercutem-se no sector agrário, com enfoque ao início tardio da sementeira e a degradação das culturas por não se adaptarem com a estiagem, ameaçando de certa forma, o rendimento agrícola.

O uso de culturas adaptativas e resilientes às mudanças climáticas; as novas tecnologias; o sistema de multicultura; a valorização e integração de iniciativas locais; disponibilização da informação; incorporação da temática das MC nas politicas públicas, entre outras estratégias, constituem alternativas para garantir o equilíbrio dos níveis de produção e assegurar a vida da população directa e/ou indirectamente afectada pelos efeitos das MC.

\section{REFERÊNCIAS BIBLIOGRÁFICAS}

Carlos, M. E. M., Santos, M. M. de O. (2009). Mudanças Climáticas e Tecnologia. Rio de Janeiro, INT/DINT.

GOVERNO DA PROVÍNCIA DO NIASSA (GPN) (2017). Plano Estratégico do Niassa 2018-2029 (PEN 2029). Lichinga.

Lima, R. da C. C., Cavalcante, A. de M. B., Perez-Marin, A. M. (2011). Desertificação e mudanças climáticas no semiárido brasileiro. Campina Grande, INSA-PB.

Maluf, R. S., Rosa, T. da S.. (2011). Mudanças climáticas, desigualdades sociais e populações vulneráveis no Brasil: construindo capacidades, subprojecto populações. Vol. 1. Rio de Janeiro.

MICOA. (2005). Avaliação da vulnerabilidade as mudanças climáticas e estratégias de adaptação. Maputo.

MICOA. (2012). Estratégia Nacional de Adaptação e Mitigação de Mudanças Climáticas (ENAMMC). Maputo.

HOLOS, Ano 36, v.7, e10281, 2020 
MICOA. (2007). Programa de Acção Nacional para a Adaptação às Mudanças Climáticas (NAPA). Maputo, DNGA.

MINISTÉRIO DA CIÊNCIA E TECNOLOGIA (MCT). Convenção sobre mudança do clima. Brasil, s/d.

MINISTERIO DO AMBIENTE E AGRICULTURA (MAA) (2007, nov.). Programa de Acção Nacional de Adaptação às Mudanças Climáticas. Cabo Verde.

Oliveira, R. di F., Alves, J. W. S. (2011). Mudanças climáticas globais no Estado de São Paulo. São Paulo, SMA,

Olivieri, A. G. (2009). A teoria da modernidade ecológica: uma avaliação crítica dos fundamentos teóricos. (Tese de doutorado, Istituto de ciencias sociais, Departamento de sociologia, Brasília, Universidade de Brasília,.

REPÚBLICA DE MOÇAMBIQUE (RM) (2019). Segundo relatório de revisão de Moçambique: mecanismo africano de revisão de pares (MARP).

Zolho, R. (2010). Mudanças Climáticas e as Florestas em Moçambique. Mocambique, CIP.

\section{COMO CITAR ESTE ARTIGO:}

Machili, B. J. (2020). As mudanças climáticas na Província do Niassa e seu impacto para a agricultura. Holos. 36 (7), 1-15.

\section{SOBRE OS AUTORES}

\section{B. J. MACHILI}

Docente do Curso de Geografia e Gestão Ambiental e desenvolvimento Comunitário (GADEC) - Universidade Rovuma, Extensão de Niassa; Director de Programa da Rede Provincial de Paralegais para Arbitragem e Desenvolvimento Sustentável - Justiça Ambiental pelas Comunidades do Niassa (REPADES-JAC Niassa); Doutorando do Curso de Doutoramento em Geografia da Universidade Pedagógica de Maputo, com Estágio Científico Avançado na Universidade do Minho em Braga - Portugal; Mestrado em Educação/Ensino de Geografia pela Universidade Pedagógica de Maputo; Licenciado em História e Geografia - Universidade Pedagógica de Nampula. E-mail: boavidajorgemachili@gmail.com ORCID ID: https://orcid.org/0000-0003-3620-1368

Editor(a) Responsável: Francinaide de Lima Silva Nascimento Pareceristas Ad Hoc: MARISA MOURA DE ABREU E AURILENE SANTOS 


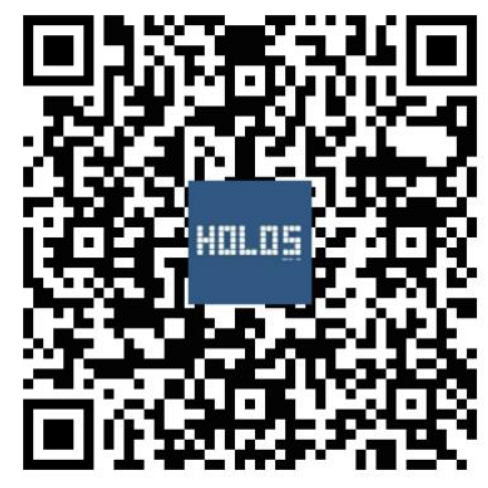

